\title{
EDITORIAL
}

\section{Relationships with technology}

Learning technologists and educational technology researchers will be familiar with scenarios where technologies are not taken up and used in the ways we expect them to be. From telephones to texting, to the web itself, there are ample examples from history of technology being appropriated in unexpected ways. This is one of the reasons why Cook and Noss (2010), in their foreword to a review of the evidence for technology enhanced learning, start out by stating that it really is somewhat fruitless to ask what is the impact of technology-in-general' (p. 4). Rather what we should be asking is how can we design technologies and the contexts into which they are inserted? Previously, design has been conceptualized as a process of understanding the media properties or affordances of technologies and the act of placing them appropriately within contexts where they could be used to facilitate particular interactions or educational practices (Conole \& Dyke, 2004; Laurillard, 2002). As the papers in this journal seem to be increasingly concerned with the people and processes involved in educational technology, it seems insufficient to think of design without a consideration of the relationships between people and technology.

The papers in this issue illustrate some of the ways in which our relationships with technology are shaping their use. In the first paper, Waycott, Dalgarno, Kennedy and Bishop show that the same technology is responded to differently by two groups of students. In their evaluation of two photo-sharing learning activities, they found that the biology students collecting and sharing photos of beetles rated the contribution of photo-sharing to their learning more positively than a group of chemistry students sharing photos of chemistry in everyday situations. While both tasks were designed as authentic learning experiences that learners could undertake as part of a cohort of peers, Waycott et al. argue that the ways in which the technology was perceived by students influenced their reactions to it. The difference in the learners' responses is discussed in terms of relevance to their needs - perhaps it was because some chemistry students did not perceive the task as relevant that they were more negative in their ratings of it.

Considering the needs of the users of technology is also highlighted in Heinrich and Milne's evaluation of teachers' use of an electronic marking tool. Their research began with a study of teachers' needs for assignment marking. In this case, although the actual tool appears to be straightforward, they found it provoked fundamental shifts in teachers' practice. Teachers reported that their use of the electronic marking tool encouraged them to create and use marking rubrics, write detailed feedback and review their own practice. Here a tool designed to improve the organization and administration of marking also appears to facilitate changes in teachers' practice.

What these first two papers show is that users of technology - whether designers, teachers or students - have agency. They can reject technologies designed to improve learning or use simple technologies in ways that significantly improve their practice. The idea that staff are active agents in deciding how technology is used is likely 


\section{Editorial}

to be familiar to those of us from a staff development background. Benson, Brack and Samarwickrema in this issue reiterate the role of staff development in supporting lecturers to integrate technologies into their teaching. Similarly, Wilson and Randall's evaluation of teaching rooms designed to encourage groupwork, show that although the new layout facilitates interaction between students to some extent, the real value comes when the teacher makes good use of the available space. Benson et al.'s and Wilson \& Randall's practice-based studies also show the value of research conducted to uncover and capture how the link between technology and pedagogy is actually made real by teachers and students in context.

The first four papers in this issue help us to see how the relationships we form with technology might be important. As a field, we are moving on from investigations of the affordances of technology itself, and even on from pedagogically informed design, towards understanding people's use of technology in context. One of the frustrations expressed in ALT's review of 'Technology in Learning' is that the substantial increase in the amount of research undertaken and published has not resulted in a coherent evidence base to inform policy and practice. What might help? First, we need to be devising research questions that help us to understand what actions designers and teachers can take to influence their students' relationships with technology. For example, rather than asking whether clickers improve learning, Terrion and Aceti in this issue locate their evaluation of learning activities designed to engage students in learning in class (through the use of clickers) within Carini, Kuh and Klein's (2006) conception of student engagement. This enables them to ask the more meaningful research question - how can technology help us to create opportunities when students become engaged?

Second, we need to be making more use of models and theories available. Gunn and Steel in this issue present their analysis of journal articles from educational technology design research, which shows that much of the published research in our field makes little reference or contribution to theoretical developments. Alison Ruth in this issue provides one example of a model that might be useful. She describes a metaphor for learning in digital environments - the 'screenface' - and offers it as a way of taking into account the different actors in the teaching and learning process. In this model, teachers, designers and learners are seen as actors who have multiple forms of agency (the manner in which they act) available to them. She draws on Winter et al.'s (2010) study of postgraduate students' boundary management in online/offline working, and Traxler's (2010) discussion of mobile devices to show how the screenface metaphor can be applied. These are two contexts (personal study habits and personal devices) where learners clearly have a good deal of choice about how they act in respect of technology use. I suspect that in other contexts as well our design must start with an understanding of how teachers and learners relate to and value the technologies they are working with.

\section{References}

Carini, R. M., Kuh, G. D. \& Klein, S. P. (2006) 'Student engagement and student learning: testing the linkages', Research in Higher Education, vol. 47, pp. 1-32.

Conole, G. \& Dyke, M. (2004) 'What are the affordances of information and communication technologies?', ALT-J, Research in Learning Technology, vol. 12, no. 2, pp. 113-124.

Cook, J. \& Noss, R. (2010) Foreword, in Technology in learning: a response to some questions from the Department of Business, Innovation and Skills. Association for 
Learning Technology and Technology Enhanced Learning Research Programme. Available at: http://repository.alt.ac.uk/839/

Laurillard, D. (2002) Rethinking university teaching: a framework for the effective use of learning technologies, $2^{\text {nd }}$ Edition. Routledge Falmer, London and New York.

Traxler, J. (2010) 'Students and mobile devices', ALT-J, Research in Learning Technology, vol. 18 , no. 2 , pp. $149-160$.

Winter, J., Cotton, D., Gavin, J. \& Yorke, J. (2010) 'Effective e-learning? Multi-tasking, distractions and boundary management by graduate students in an online environment', ALT-J, Research in Learning Technology, vol. 18, no. 1, pp. 71-83.

Rhona Sharpe

Oxford Centre for Staff and Learning Development

Oxford Brookes University, UK 